\section{International Scientific Journal Theoretical \& Applied Science}

p-ISSN: 2308-4944 (print) e-ISSN: 2409-0085 (online)

Year: $2014 \quad$ Issue: 12 Volume: 20

Published: $30.12 .2014 \quad \underline{\text { http://www.T-Science.org }}$
Anna Sergeevna Kravchenko PhD student of Department «Economic analysis» Kuban State Agrarian University, Krasnodar, Russia anna.kravchenko.92@inbox.ru

SECTION 31. Economic research, finance, innovation, risk management.

\title{
COMPREHENSIVE ASSESSMENT OF THE EFFECTIVENESS OF THE BUSINESS ACTIVITIES OF AGRICULTURAL ORGANIZATIONS
}

Abstract: Showing the dependence between the availability of resources and the efficiency of their use. Evaluated influence of the speed of the production process, the efficiency of commercial operations and structural relations in assets and liabilities on the overall effectiveness of the business. Defined quantification influence of these factors.

Key words: analysis, economic efficiency, resources, productivity, capital, asset turnover, return on sales, return on assets.

Language: Russian

Citation: Kravchenko AS (2014) COMPREHENSIVE ASSESSMENT OF THE EFFECTIVENESS OF THE BUSINESS ACTIVITIES OF AGRICULTURAL ORGANIZATIONS. ISJ Theoretical \& Applied Science 12 (20): 53-56. doi: http://dx.doi.org/10.15863/TAS.2014.12.20.12

\section{КОМПЛЕКСНАЯ ОЦЕНКА ЭФФЕКТИВНОСТИ ПРЕДПРИНИМАТЕЛЬСКОЙ ДЕЯТЕЛЬНОСТИ СЕЛЬСКОХОЗЯЙСТВЕННЫХ ОРГАНИЗАЦИЙ}

Аннотация: Установлена зависимость между наличием ресурсов и эффективностью их использования. Оиченено влияние скорости производственного процесса, эффективности коммерческих операций и структурных соотношений в активах и пассивах на общую эффективность бизнеса. Дана количественная оценка влияния этих факторов.

Ключевые слова: анализ, экономическая эффективность, ресурсы, производительность труда, капитал, оборачиваемость активов, рентабельность продаж, рентабельность активов.

Для оценки эффективности деятельности организаций применяется большое количество показателей, характеризующих как эффективность использования отдельных видов ресурсов и элементов производственного процесса, так и обобщающие показатели [3]. Нередко эти показатели не взаимосвязаны между собой и могут изменяться в противоположных направлениях, что затрудняет их интерпретацию и может привести к принятию неправильных управленческих решений.

Между тем, очевидно, что для повышения эффективности работы организации необходимо комплексное развитие всех сторон ее финансовохозяйственной деятельности, рациональное и системное использование всех ресурсов [5]. При этом необходимо учитывать, что хозяйствующие субъекты в разной степени обеспечены ресурсами и обладают не одинаковыми возможностями по их расширению.

Учитывая все вышеизложенное, мы разработали интегральную систему показателей для комплексного анализа экономической эффективности предпринимательской деятельности организаций. В ее основу легла трехзвенная структура: от уровня обеспеченности отдельным видом ресурсов перейти к эффективности его использования, а от нее к некому показателю, характеризующему общую эффективность финансово-хозяйственной деятельности, который интегрировал бы воздействие отдельных факторов.

В качестве такого показателя была выбрана рентабельность активов. Она показывает, сколько рублей чистой прибыли получает предприятие на каждый рубль, вложенный в активы, т.е. характеризует соотношение конечного результата всей деятельности (чистой прибыли) с
ISPC European Research,

Birmingham, United Kingdom 
совокупной стоимостью имущества, используемого для его получения.

Для анализа и оценки эффективности финансово-хозяйственной деятельности нами были отобраны 170 средних и крупных сельскохозяйственных организаций Краснодарского края.

Поскольку общая эффективность предпринимательской деятельности определяется не только степенью эффективности использования отдельных видов ресурсов, но и другими факторами, то анализ проводился по нескольким направлениям:

1) эффективность использования основных видов ресурсов (основные средства, трудовые и материальные ресурсы).

2) скорость производственного процесса и эффективность коммерческих операций;

3) структурные соотношения в имуществе и источниках его финансирования.

В результате проведенного исследования было выявлено:

1) между степенью обеспеченности ресурсами и эффективностью их использования существует обратная зависимость: чем в меньшей степени предприятие обеспечено ресурсами, тем более эффективно оно их использует, и наоборот.

Это можно объяснить следующим образом: меньшим количеством ресурсов проще управлять и ввиду их ограниченности нагрузка на каждую единицу возрастает, что заставляет более рационально подходить к вопросам организации труда и планирования технологического процесса, чтобы уменьшить простои оборудования.

Вместе с тем, из этого не следует вывод о том, что для повышения эффективности использования ресурсов нужно снижать обеспеченность ими. Недостаток ресурсов также отрицательно сказывается на результатах деятельности, как и их избыток. Например, недостаток основных средств приводит к увеличению затрат времени и труда на совершение технологических процессов, а их избыток ведет к увеличению себестоимости производства, вследствие роста затрат на содержание и обслуживание неиспользуемой техники;

2) между частными показателями эффективности использования отдельных видов ресурсов и интегральным показателем прослеживается прямая зависимость.

При росте фондоотдачи наблюдается увеличение коэффициента оборачиваемости имущества и рентабельности активов, характеризующих получение выручки и чистой прибыли на каждый рубль, вложенный в активы предприятия. Так, по группе хозяйств с фондоотдачей от 0,2 до 0,9 руб. на каждый рубль, вложенный в активы, наблюдается отдача в размере 37 коп. выручки и 4 коп. чистой прибыли, а при фондоотдаче свыше 3 руб. вышеуказанные показатели составляют 89 и 16 коп. соответственно.

Между производительностью труда, коэффициентом оборачиваемости имущества и рентабельностью активов также существует прямая связь. Так, при средней производительности труда 643,1 тыс. руб. хозяйства исследуемой совокупности на каждый рубль, вложенный в активы, получают 58 коп. выручки и 6 коп чистой прибыли. А при производительности труда свыше 2000 тыс. руб. - 71 коп. выручки и 15 коп. чистой прибыли.

Аналогичная связь наблюдается и по материалоотдаче. При материалоотдаче от 0,7 до 1,2 руб. хозяйства получают в среднем 59 коп. выручки и 7 коп. чистой прибыли в расчете на 1 рубль, вложенный в имущество, а по группе с наибольшей материалоотдачей (в среднем 2,9 руб.) - 65 и 14 коп. соответственно;

3) скорость производственного процесса и эффективность коммерческих операций оказывают прямое влияние на рентабельность активов.

Рост коэффициента оборачиваемости оборотных активов сопровождается увеличением отдачи с каждого рубля, вложенного в активы: предприятия первой группы получают 34 коп. выручки и 6 коп. чистой прибыли, а пятой группы - 87 коп. выручки и 13 коп. чистой прибыли.

По мере роста рентабельности продаж также увеличивается эффективность использования всего имущества в целом. Так, при средней рентабельности продаж $5,8 \%$ организации исследуемой совокупности на каждый рубль, вложенный в имущество, получают 3 коп. чистой прибыли. А организации с рентабельностью продаж от 30 до 41\% - в среднем 18 коп;

4) структура имущества и источников его образования влияет на эффективность предпринимательской деятельности.

Наибольшая эффективность использования имущества наблюдается по пятой группе хозяйств с значениями коэффициента автономии от 0,70 до 0,86 пункта. Предприятия этой группы на каждый рубль, вложенный в имущество, получали 70 коп. выручки и 11 коп. чистой прибыли. При этом ранее проведенный анализ также показал, что доля собственных средств у наиболее рентабельных предприятий составляет в среднем $78 \%$.

При росте обеспеченности собственными оборотными средствами в среднем до уровня $62,7 \%$ отмечается рост эффективности финансово-хозяйственной и коммерческой деятельности предприятий. Наибольшие 
значения коэффициента оборачиваемости имущества - 0,724 пункта, рентабельности активов - 13,4\% и продаж - 19,81\% выявлены по группе хозяйств с значениями коэффициента обеспеченности собственными оборотными средствами от 0,5 до 0,75 пункта.

По мере роста рентабельности активов соотношение между внеоборотными и оборотными средствами сдвигается в сторону $40 \%$ на $60 \%$.

В структуре внеоборотных активов отмечается рост доли основных средств и снижение доли долгосрочных финансовых вложений.

В структуре оборотных активов наблюдается увеличение доли запасов (с 22,2\% у убыточных предприятий до $35 \%$ у предприятий со средней рентабельностью 19,7\%) и краткосрочных финансовых вложений (с 3\% до $25 \%$ ). Это объясняется стремлением организаций диверсифицировать риски хозяйственной деятельности. Вложение средств в высоколиквидные ценные бумаги гарантирует сбалансированность финансовых ресурсов, особенно необходимую вследствие сезонного характера производства, и обеспечение определенного запаса финансовой прочности для предотвращения возможных негативных последствий в результате непредвиденных факторов: неблагоприятные климатические условия, обвал продовольственного рынка и т.д.

Анализ структуры источников образования имущества показал, что увеличение доли собственных средств способствует росту рентабельности активов. У наиболее рентабельных предприятий доля собственных средств увеличивается до 78\%, а заемных, соответственно, снижается до 22\%. При этом доля краткосрочных обязательств в 2,3 раза больше доли долгосрочных.

В структуре собственного капитала по мере роста рентабельности активов наблюдается увеличение доли нераспределенной прибыли с $17,7 \%$ у убыточных предприятий до $63,9 \%$ у наиболее прибыльных.

Увеличение доли собственного капитала происходит за счет сокращения доли долгосрочных заемных источников с 22,9\% у убыточных предприятий до 5,8\% у наиболее рентабельных. Доля краткосрочных обязательств практически не изменяется и составляет в среднем $22 \%$.
Для количественной оценки влияния рассмотренных факторов на величину рентабельности активов по совокупности исследуемых организаций края нами было построено уравнение множественной регрессии:

$$
\begin{gathered}
\mathrm{y}=1,522+0,035 \times \mathrm{x}_{1}+0,005 \times \mathrm{x}_{2}+0,021 \times \mathrm{x}_{3}+ \\
+0,251 \times \mathrm{x}_{4}+0,031 \times \mathrm{x}_{5}-0,06 \times \mathrm{x}_{6}+0,883 \times \mathrm{x}_{7} .
\end{gathered}
$$

В качестве результативного признака (у) была выбрана рентабельность активов. Факторными показателями стали:

$\mathrm{x}_{1}$ - фондорентабельность, \%;

$\mathrm{x}_{2}$ - величина чистой прибыли в расчете на 1 работника, занятого в сельском хозяйстве, тыс. руб.;

$\mathrm{x}_{3}$ - величина чистой прибыли в расчете на 100 рублей материальных затрат, руб.;

$\mathrm{x}_{4}$ - рентабельность оборотных активов, \%;

$\mathrm{x}_{5}$ - рентабельность продаж, \%;

$\mathrm{x}_{6}$ - коэффициент концентрации собственного капитала;

$\mathrm{x}_{7} \quad-\quad$ коэффициент обеспеченности собственными оборотными средствами.

Первые три фактора характеризуют эффективность использования основных видов ресурсов, следующие два - эффективность коммерческих операций, последние два качественные соотношения в имуществе и источниках его формирования.

Множественный коэффициент корреляции $\mathrm{R}$ составил 0,927 пункта, что указывает на очень сильную, почти функциональную связь между рентабельностью активов и комплексом факторных признаков. Коэффициент детерминации $\mathrm{R}^{2}$ равен 0,859 пункта. Это означает, что полученное линейное уравнение объясняет варьирование рентабельности активов на $85,9 \%$, оставшиеся $14,1 \%$ приходятся на неучтенные в модели факторы.

Проведенное исследование позволило получить представление о существующих взаимосвязях и взаимозависимостях между разрозненными показателями эффективности. Комплексный учет этих факторов позволит обосновать основные направления повышения эффективности предпринимательской деятельности сельскохозяйственных организаций Краснодарского края, а также определить стратегию и сбалансированность развития конкретных субъектов хозяйствования.

\section{References:}

1. Brighjem J, Jerhardt M (2009) Finansovyj menedzhment. 10-e izd. / Per s angl. pod red. k.je.n. E. A. Dorofeeva. - SPb.: Piter, 960.
2. (2010) Finansovyj menedzhment: teorija i praktika: uchebnik / Pod red. E.S. Stojanovoj. 6-e izd. - M.: Izd-vo «Perspektiva», 656. 
3. Kogdenko VG (2011) Jekonomicheskij analiz: uchebnik. - 2-e izd., pererab. i dop. - Moscow: JuNITI-DANA, 399.

4. Kovalev VV (2008) Kurs finansovogo menedzhmenta: ucheb. - Moscow: TK Velbi, Izd-vo Prospekt, 448.

5. Ljubushin NP (2010) Jekonomicheskij analiz: uchebnik 3-e izd., pererab. i dop. - Moscow: JuNITI-DANA, 575.

6. Mejer, Marshal V (2004) Ocenka jeffektivnosti biznesa / Marshal V. Mejer; [Per. s angl. A. O. Korsunskij]. - Moscow: OOO «Vershina», 272.

7. Pereverzev MP, Lunjova AM (2009) Osnovy predprinimatel'stva: uchebnik / Pod obshh. red. prof. M.P. Pereverzeva. - Moscow: INFRA-M, 176.

8. Savickaja GV (2014) Analiz jeffektivnosti i riskov predprinimatel'skoj dejatel'nosti. Metodologicheskie aspekty / G. V. Savickaja.Moscow: Infra-M, 272.

9. Sheremet AD (2006) Kompleksnyj analiz hozjajstvennoj dejatel'nosti. - Moscow: INFRA-M, 415.

10. Vahrushina MA (2010) Upravlencheskij analiz: ucheb. posobie dlja studentov, obuchajushhihsja po spec. «Buhgalterskij uchet, analiz i audit» / M.A. Vahrushina. - 6-e izd., ispr. - Moscow: Izdatel'stvo «Omega-L», 399. 